methods). Those wishing to read papers $(10-20$ min. duration) must send a short summary before February 1955. All inquiries relative to the Congress should be directed to the Secretary-General, XIVth International Congress of Pure and Applied Chemistry, Zurich 1.

\section{Autoradiography Course at Harwell}

A SPECIAL course on autoradiographic techniques will be held in the Isotope School, Harwell, during December 13-16 under the direction of Dr. S. R. Pelc, of Hammersmith Hospital, London. Lectures will be given on the theory of the photographic process; photographic action of electrons; estimation of radiation damage; calculation of concentration of tracer necessary to produce autoradiographs; biological results of investigations using autoradiographic techniques; and design of autoradiographic experiments. Demonstrations will include the squashing technique applied to bean roots grown in phosphorus32 ; stripping film technique ; autoradiography using stripping film technique; and use of phase-contrast microscope. Practical work will include squash preparations for autoradiography, for example, bean root ; autographs of sectioned material using stripping film technique; and processing and staining of autoradiographs using normal and phase-contrast microscopes. The fee for the course is $£ 8$. Accommodation in local inns can be arranged if required. Applications should be made to the Isotope School, A.E.R.E., Harwell, near Didcot, Berkshire.

\section{Water Pollution Research Laboratory: New Premises}

ON October 1 the Water Pollution Research Laboratory will move from its temporary premises in Watford, Birmingham and elsewhere to a new permanent building in Elder Way, Stevenage, Herts ; it is not likely that an official opening will take place before the spring. The new premises include a threestory block, containing administrative offices, an information section and microbiological, chemical and physical laboratories. There are also four pilotscale laboratories and facilities for building larger experimental plant in the open. Special facilities have been provided for experimental work on the treatment of sewage and industrial wastes, including a radiochemical section which will be concerned at first particularly with problems of disposing of radioactive liquids. Two of the pilot laboratories are designed for experiments on the effect of pollution. on fish; this work is carried out in collaboration with a team of biologists of the Ministry of Agriculture and Fisheries.

\section{The Night Sky in October}

Futl moon occurs on Oct. 12d. 05h. $10 \mathrm{~m}$., U.í., and new moon on Oct. $26 \mathrm{~d} .17 \mathrm{~h} .47 \mathrm{~m}$. The following conjunctions with the moon take place: Oct. 5d. 24h., Mars $4^{\circ}$ S. ; Oct. 19d. 04h., Jupiter $2^{\circ}$ N.; Oct. 26d. 23h., Venus $3^{\circ} \mathrm{S}$. In addition to these conjunctions with the moon, Jupiter is in conjunction with Uranus on Oct. $8 \mathrm{~d}$. $04 \mathrm{~h}$., Jupiter being $0.4^{\circ} \mathrm{S}$.; Mercury is in conjunction with Saturn on Oet. 9d. $1 \mathrm{~h}$., Mercury $5 \cdot 6^{\circ} \mathrm{S}$, and again on Oct. $24 \mathrm{~d}$. $1 \mathrm{lh}$. when Mercury is $4.7^{\circ} \mathrm{S}$. Mercury, an evening star throughout most of the month, sets too soon after the sun to be observed. Venus sets about forty minutes after sunset at the beginning and middle of the month and about the time of sunset at the end of the month, and will not be favourably placed for observation. Mars, an evening star, sets about $22 \mathrm{~h}$. $10 \mathrm{~m}$. during the month, but it lies rather low for good observation in the British Isles. Jupiter rises at $23 \mathrm{~h} .20 \mathrm{~m} ., 22 \mathrm{~h} .35 \mathrm{~m}$. and $21 \mathrm{~h} .40 \mathrm{~m}$. at the beginning, middle and end of the month, respectively, and will be conspicuous in the constellation Cancer, its stellar maignitude varying from -1.7 to $-1 \cdot 8$. Saturn sets at $18 \mathrm{~h} .45 \mathrm{~m}$. and $17 \mathrm{~h} .55 \mathrm{~m}$. on October 1 and 15 , respectively, and is in conjunction with the sun early in November; throughout most of the month it is unfavourably placed for observation. Occultations of stars brighter than magnitude 6 are as follows, observations being made at Greenwich: Oct. 15d. 01h. 40.8m., 33 Taur. $(R)$; Oct. 15d. $23 \mathrm{~h}$. $35 \cdot 7 \mathrm{~m} ., 99$ Taur. $(R)$; Oct. 16d. 04h. $45 \cdot 5 \mathrm{~m}$., 103 Taur. $(R) ; R$ refers to reappearance. The Orionid meteor shower attains its maximum about October $20-23$; the radiant of this shower is close to $\gamma$ Geminorum.

\section{Announcements}

WE regret to announce the death of Dr. André Donatien, correspondant for the Rural Economy Section of the Paris Academy of Sciences and chef de service of the Pasteur Institute of Algeria, on August 10 , aged sixty-four.

Mr. H. S. TASKER has been elected a Fellow of the Institute of Metals, in recognition of his distinguished services to the. Institute; the total number of Fellows is limited to twelve. Mr. Tasker was president of the Institute during 1950-51, and has been chairman of its Finance and General Purposes Committee (1940-44) and honorary treasurer (1945-47).

THE French Metallurgical Society will, as in former years, hold its "Journées Métallurgiques d'Automne" in Paris during October 25-30. Further information can be obtained from the Société Française de Métallurgie, 25 rue de Clichy, Paris $9^{\mathrm{e}}$.

ThE dates of the meeting of the Meteorologische Gesellschaft in Hamburg, to be held in Hamburg in honour of the centenary of the birth of G. Hellmann (see Nature, May 15, p. 896), have been changed to October 8-11.

The Swiss Federal Commission for studying Hail Formation and Hail Prevention will hold an international symposium on experimental meteorology at the Swiss Federal Institute of Technology, Zurich, during October 4-6. The symposium will discuss primarily the question of the natural processes of rain and the methods of influencing it, as well as the problem of the formation of hail and its possible prevention. Further information can be obtained from the president of the Commission, Prof. R. Sänger, E.T.H., Postfach, Zurich 23.

Issurd annually, with some interruptions, since 1915 , the "Subject Index to Periodicals" is now being published quarterly with annual cumulations. The first of these quarterly issues covers January to March 1954 (pp. 71. London: Library Association), and the three hundred British periodicals indexed have been carefully selected to meet the needs of the smaller as well as the larger public library, and those of academic and special libraries. How far the greater frequency of publication enables the "Index" to keep pace more closely with the influx of material cannot fairly be judged from a single issue, and the full advantage will probably be derived in the annual cumulation. 